\title{
Analysis of tools for assessing the terms of working environment of foreigners
}

\author{
Anna Svetlakova ${ }^{1, *}$, Tatiana Kaverzneva ${ }^{1}$, Dmitriy Tarkhov $^{1}$, and Natalia Belina ${ }^{1}$ \\ ${ }^{1}$ Peter the Great St. Petersburg Polytechnic University, Polytechnicheskaya 29, St. Petersburg, \\ 195251, Russian Federation.
}

\begin{abstract}
The critical review presents an analysis of foreign studies designed to assess the state of working conditions. The aim of the work is to identify the main areas of research that can be adapted for Russian enterprises. It was found that there are several foreign instruments for assessing the state of working conditions, on the basis of which a new methodology applicable to Russian enterprises can be formed, which will greatly contribute to the prevention of accidents at the workplace.
\end{abstract}

\section{Introduction}

In industrialized countries, activities aimed at preventing occupational injuries are quite successful. In Quebec, Canada, the number of cases decreased by 50,000 from 1997 to 2013 [1]. This is primarily due to the fact that the labor protection system of developed countries is focused on the prevention of accidents and occupational diseases, and in Rus-sia there is an emphasis on eliminating their consequences [2]. The analysis of foreign ap-proaches to the assessment of the state of working conditions will identify the most power-ful aspects that will allow to formulate a methodology adapted for Russian enterprises. The state of working conditions is one of the important indicators of the effectiveness of labor protection [3]. Some researchers have defined the effectiveness of labor protection as the ability of enterprises to prevent occupational injuries [4]. Others have identified it as the lack of occupational accidents and occupational diseases or injuries for a long period of time [2]. For the purposes of this study, a definition of the effectiveness of labor protection based on two specific criteria was adopted:

- Business works well if its OSH management is effective [2];

- Occupational health and safety management is effective if it leads to the reduction or elimination of occupational injuries and illnesses both in the short and long term [5].

Assessment of the state of working conditions is carried out mainly using performance indicators. The indicator of effectiveness is the measurement of the indicator, which is considered to be the main one for the model under study [6]. In the foreign literature, two types of indicators are described that are used in assessing working conditions: reactive and proactive. The first allow to assess the impact of the actions taken on OSH management. The most frequently used reactive indicators is the frequency of accidents and the degree of their

\footnotetext{
* Corresponding author: 89027910153@mail.ru
} 
severity. However, the evaluation of the effectiveness of labor protection, based solely on reactive indicators, is incomplete [7]. For the detailed analysis, proactive indicators are used, which are a measure of the progress achieved by preventive activities. An exam-ple is the frequency of inspections at the workplace [8].

\section{Materials and methods}

The purpose of this study is to provide an overview of foreign instruments currently used to assess the state of working conditions and to determine which of them can be adapted for Russian enterprises. To achieve this goal, the literature review was organized as follows: (1) the literature search method; (2) the selection of relevant publications; (3) retrieval and classification of data; (4) discussion of research. Then, articles containing key words such as working conditions, productivity, occupational health, safety, indication, evaluation, analysis, quantification, qualitative assessment, safety program, security audit, construc-tion, model and tools were selected. Searching was carried out in English by groups of keywords, combined with the use of "AND" or "OR" operators. The publications obtained in this way were used as a basis for the study of tools for assessing the state of working conditions and the effectiveness of OSH management. The analysis of names, keywords and theses was carried out. The study included only research articles subjected to peer re-view, research reports, standards and laws. Thus, 43 peer-reviewed publications were ana-lyzed. The main criteria for selecting tools for assessing the state of working conditions are shown in Figure

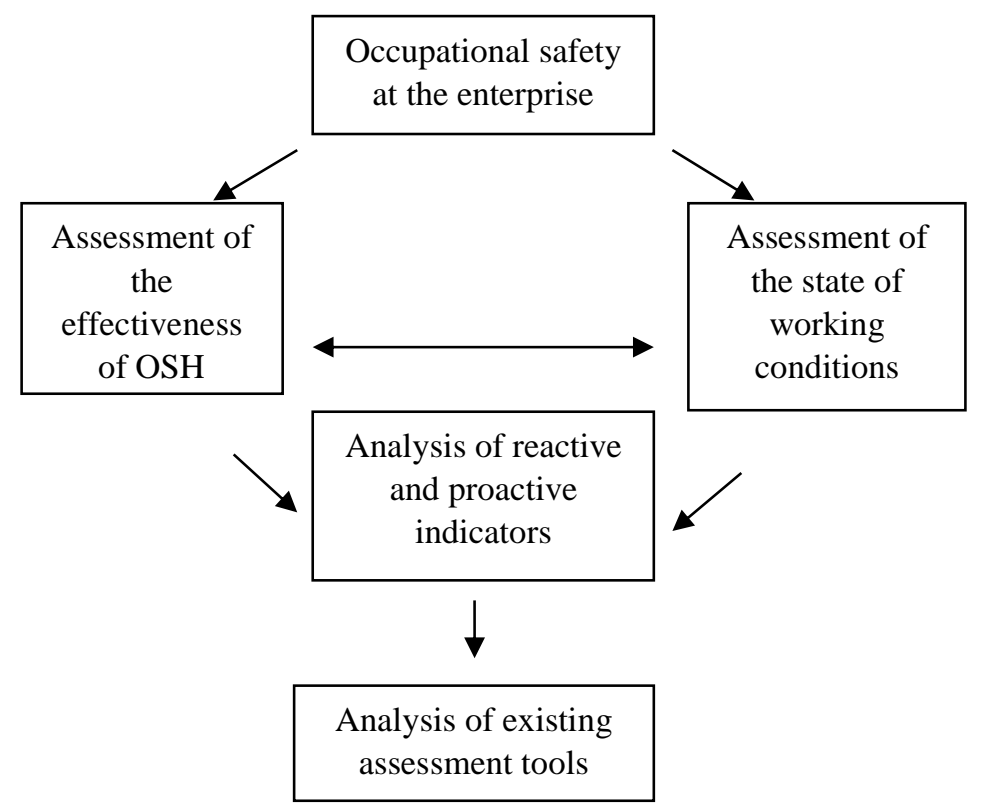

Fig. 1. Interrelation of the main criteria for selecting tools for assessing the state of working conditions.

\section{Results}

In accordance with the applied methodology, six performance evaluation tools have been selected from the scientific literature published since 2005 and are described in detail. To assess the conformity of the foreign instruments examined by Russian enterprises, the following characteristics of these instruments were analyzed first: 
- Reliability of the content. It helps to determine whether it is possible to use the tool to evaluate six elements that can contribute to improving the condition of working environment. These elements are: senior management competence, risk management, training, the competence of production managers, safe behavior and the prevention of accidents using the continuous improvement approach [8, 9-13].

- Combined use of indicators of both types. To obtain an overall assessment of the effectiveness of the use of tools, it is necessary that they include both reactive and proactive indicators [14].

- Simplicity. The approach to assessing the state of working conditions should be simple and inexpensive [9].

- Reliability. It is defined as the similarity of results obtained with the help of a tool performed by different specialists [15].

The analysis of the literature showed that since 2005 only 6 new tools for assessing the state of working conditions have been described (others are the intellectual property of private business and are not included in the analysis).

Tool 1. Corporate health and safety performance Index

Experts on accident prevention have developed a list of preventive measures aimed at improving working conditions, consisting of 10 proactive indicators related to the following activities: manual handling of cargo, repetitive motion, use of chemicals, work at height, contact with unprotected equipment components, etc. Further analysis is carried out on a twolevel Likert scale. A score of 1 point shows that the indicator is not used or is missing, in 2 points - that the indicator is used or present. For the enterprise the maximum score is calculated taking into account all types of work carried out, with which the summed-up evaluations are subsequently compared. The magnitude of the deviation from the maxi-mum score characterizes the state of working conditions at the given enterprise [16].

Tool 2. Occupational health and safety self-diagnostic tool

The evaluation tool is intended for use in manufacturing plants. This is, in fact, a questionnaire composed entirely of proactive indicators, which must be filled with workers. Examples of questions: are all the necessary protective devices installed on the equipment; whether preventive maintenance of the equipment is carried out regularly; whether the company provides the necessary personal protective equipment. All personnel are in-volved. However, the evaluation has limitations: the subjectivity of the staff's opinion is superimposed. This problem is suggested by the authors of the approach, not considering the answers of workers who have an unreasonably negative or positive view, thereby in-creasing the reliability of the tool [7].

Tool 3. Project safety index

The tool is a combination of reactive and proactive indicators that allow a comprehensive assessment of the working conditions. An arbitrarily given time interval is chosen, for which it is necessary to assess (from month to year). A survey of employees is conducted, aimed at a comprehensive analysis of the state of working conditions. It, in combination with proactive and reactive indicators, facilitates the interpretation of evaluation results and the identification of corrective measures [17].

Tool 4. Organizational performance metric

The tool is based on the analysis of 8 proactive indicators, such as regularity of inspection, the degree of preparedness of personnel, observance of safety precautions, the equipment of personnel with personal protective equipment etc.

The representative of the labor protection department or the manager of the company fills out the questionnaire and assesses the state of the working conditions on the basis of the degree of thoroughness of each of the indicators studied. [18].

Tool 5. Total safety performance 
The method uses 25 proactive indicators, divided into three dimensions: organizational (emergency plan, personal protective equipment, risk control, etc.), technical (investigation of accidents, training, monitoring of the working environment, etc.) and behavioral ones, which are estimated by the five-point Likert scale [6].

Tool 6. Building information modeling

The tool is designed for large construction companies, it is popular, and it represents a digital representation of the construction process at each stage: from design to operation [19]. Studies show that the tool can improve the quality of safety management through planning, tracking the progress of construction, consistency and visualization of the pro-ject, data integration, cost estimation at each stage of the construction process [20].

\section{Discussion}

Assessment of the effectiveness of OSH management and the state of working conditions is complex and focused on several elements, including management obligations and risk management [6]. Evaluation tools are often based on reactive indicators. Despite the simplicity of the measurement, this type of indicator provides little useful information for identifying shortcomings in the system for assessing the state of working conditions [13]. Researchers are beginning to pay attention to proactive indicators as a way of obtaining more accurate estimates. But their use is largely unknown in the scientific literature [8, 17-19]. To obtain a full evaluation, both types must be used simultaneously [18]. Table 1 shows the matching rates of the six selected tools with the four test criteria, and the degree of applicability of each instrument to Russian enterprises.

Table 1. Comparative analysis of research tools for assessing the state of working conditions.

\begin{tabular}{|c|c|c|c|c|c|}
\hline \multirow{2}{*}{ Tool } & \multicolumn{3}{|c|}{ Criteria } & Combined \\
\cline { 2 - 5 } & $\begin{array}{c}\text { Reliability } \\
\text { of content } \\
\text { indicators } \\
\text { of both } \\
\text { types }\end{array}$ & Simplicity & $\begin{array}{c}\text { Reliabil } \\
\text { ity }\end{array}$ & $\begin{array}{c}\text { Degree of } \\
\text { applicability } \\
\text { to Russian } \\
\text { enterprises }\end{array}$ \\
\hline $\begin{array}{c}\text { 1. Corporate health } \\
\text { and safety } \\
\text { performance Index }\end{array}$ & Yes & Yes & Yes & No & $\begin{array}{c}\text { Applicable } \\
\text { with } \\
\text { modifications }\end{array}$ \\
\hline $\begin{array}{c}\text { 2. OHS self- } \\
\text { diagnostic tool }\end{array}$ & $\begin{array}{c}\text { Data not } \\
\text { available }\end{array}$ & No & No & Yes & $\begin{array}{c}\text { Not } \\
\text { applicable }\end{array}$ \\
\hline $\begin{array}{c}\text { 3. Project safety } \\
\text { index }\end{array}$ & Yes & Yes & Yes & No & $\begin{array}{c}\text { Not } \\
\text { applicable }\end{array}$ \\
\hline $\begin{array}{c}\text { 4. Organizational } \\
\text { performance metric }\end{array}$ & No & No & Yes & Yes & $\begin{array}{c}\text { Applicable } \\
\text { with } \\
\text { modifications }\end{array}$ \\
\hline $\begin{array}{c}\text { 5. Total safety } \\
\text { performance }\end{array}$ & Yes & No & Yes & No & $\begin{array}{c}\text { Applicable } \\
\text { with } \\
\text { modifications }\end{array}$ \\
\hline $\begin{array}{c}\text { 6. Building } \\
\text { information } \\
\text { modeling }\end{array}$ & Yes & No & No & Yes & $\begin{array}{c}\text { Applicable } \\
\text { with } \\
\text { modifications }\end{array}$ \\
\hline
\end{tabular}




\section{Conclusions}

The assessment of the effectiveness of management of labor protection and the state of working conditions is an important step in the process of optimizing the labor process. During the period under study, foreign scientists have developed several methods for assessing the state of working conditions in business and production, where the tasks of employees are related to various risks. The review showed that at the moment there is no perfect method to perform a comprehensive analysis of the state of working conditions and the effectiveness of OSH management. Considering the merits and shortcomings of the meth-ods studied it will be possible to formulate a new methodology adapted to Russian enter-prises for a comprehensive assessment of working conditions.

\section{References}

1. Annual report of activities. Commission of Occupational Safety and Health. Montreal, Canada. CSST, (1997)

2. N.K. Kulbovskaya, Economics of Occupational health and safety, Economica, Moscow, (2011).

3. K.R. Malayan, Life Saf., 3, 3-14 (2016).

4. K.R Malayan, V.V.Milokhov, V.M. Minko, O.N.Rusak, S.A.Faustov, V.V. Tsaplin, A.D. Tsvetkova, Life Saf., 12, 3-17 (2014).

5. V.N. Mjasnikov., V.I. Salkucan, Life Sci. J., 10, 225-227 (2014).

6. D. Walker, R. Tait, D. Walker, Saf. Sci., 42, 69-83 (2004).

7. M. Roy, J. Cadieux, L. Fortier, L. Leclerc, IRSST, Montreal, 36 (2008).

8. T. Reiman, E. Pietikäinen, Saf. Sci., 50 (10) (2012).

9. P. Hasle, H.J. Limborg, Ind. Health, 44, 6-12 (2006).

10. R.B.M. De Koster, D. Stam, B.M.Balk, J. Operat. Manage, 29, 753 (2011).

11. A. Badri, A. Gbodossou, S. Nadeau, Saf. Sci., 50, 190-198 (2012).

12. J. Hinze, S. Thurman, A. Wehle, Saf. Sci., 51, 23-28 (2013).

13. Y.J. Liu, J.L Chen, S.Y. Cheng, M.T. Hsu, C.H. Wang, Process Saf. Prog., 33, 166-171 (2014).

14. S. Sinelnikov, J. Inouye, S. Kerper, Saf. Sci., 72, 240-248 (2015).

15. L.S. Robson, L.P. Bigelow, Canad. Public Health Assoc., 101, 535-540 (2010).

16. M.Wright, J.N .Doyle, S. Marsden, M. Bendig, J. Shaw, Development of a SME Version of the Corporate Health and Safety Performance Index (HSE, Berkshire), 307-318 (2005).

17. H. Lingard, R. Wakefield, P. Cashin, Eng. Constr. Arch. Manage, 18, 30-49 (2011).

18. B. Amick, A. Farquhar, K. Grant, S. Hunt, Saf. Sci., 48, 18-36 (2011).

19. C. Eastman, P. Teicholz, R. Sacks, K. Liston, BIM handbook: a guide to building information modeling for owners, managers, designers, engineers and contractors , 65 (2011).

20. W. Li, W. Liang, L. Zhang, Q. Tang, J. Loss Prev. Process Ind., 35, 95-103 (2015). 